\title{
Complete heart blocks and in-hospital mortality after ST segment elevation myocardial infarction.
}

\footnotetext{
1. MBBS, FCPS (Cardiology) Assistant Professor Cardiology Nawaz Sharif Medical College, University of Gujrat

2. MBBS, MD (Gastroenterology)

Assistant Professor

Gastroenterology

Nawaz Sharif Medical College, University of Gujrat.

3. MBBS, FCPS (Cardiology) Senior Registrar

Punjab Institute of Cardiology, Lahore.

4. MBBS, FCPS (Anesthesia)

Assistant Professor Anesthesia

Nawaz Sharif Medical College, University of Gujrat

5. MBBS, FCPS (Anesthesia) Assistant Professor Anesthesia Nawaz Sharif Medical College, University of Gujrat.

6. MBBS

Medical Officer

Aziz Bhatti Shaheed Teaching

Hospital, Gujrat.
}

Correspondence Address:

Dr. Irfan Younus

Department of Gastroenterology

Aziz Bhatti Shaheed Teaching

Hospital,

NSMC/ UOG Gujrat.

irfanyounis7887@gmail.com

Article received on:

29/09/2020

Accepted for publication:

$19 / 11 / 2020$

\section{INTRODUCTION}

Complete heart block is a common complication after acute myocardial infarction. ${ }^{1}$ Past studies showed the incidence of complete heart block after STEMI is between 3 to 13 percent. ${ }^{2,3}$ The AV blocks complicating STEMI are associated with adverse outcomes. ${ }^{4}$ Risk of complete heart block in STEMI is more than non- STEMI. ${ }^{5}$ With the use of thrombolytic therapy overall mortality decreased but incidence of AV blocks persist. ${ }^{6}$ The frequency of in hospital mortality complicated by complete heart block is more than those without complete heart block (20.4 vs 8.7)..$^{7}$ The purpose of this study is to determine the frequency of complete atrioventricular

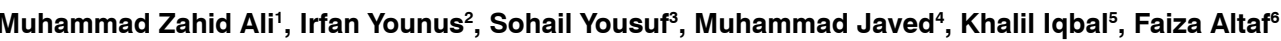
dients AV bus. Tho blocks. Incidence and mortality of CHB after STEMI noted. Data was analyzed with SPSS -23 . first group 7 out of 10 having CHB were expired, 2 discharged and one referred for permanent pacemaker or revascularization. In second group $23(15 \%)$ expired out of $157,110(70 \%)$ Complete heart block is a known complication of patients with STEMI and is associated with $\mathrm{CHB}$ in most of the patients.

Key words: Complete Heart Block, In-Hospital Mortality, ST-Elevation Myocardial

Article Citation: Ali MZ, Younus I, Yousuf S, Javed M, Iqbal K, Altaf F. Complete heart blocks Professional Med J 2021; 28(7):1049-1052. https://doi.org/10.29309/TPMJ/2021.28.07.6115

block in patients with acute STEMI as well as to determine the in-hospital outcome in them. So this study will help in designing a protocol and recommendations for the management of these high risk patients presenting to non-invasive cardiology departments to reduce the morbidity and mortality of our community.

\section{MATERIAL \& METHODS}

This was a comparative cross sectional study. Patients meeting selection criteria were taken in the study through the CCU of ABSTH/NSMC Gujrat after their informed consent. Patients between the ages of 35 to 65 years of both genders with STEMI followed by thrombolysis 
were included in the study whereas patients with prior history of $\mathrm{MI}, \mathrm{PCl}$ or CABG or patients with prior AV blocks were excluded from the study. All patients remained admitted and followed up for 3 to 5 days. Patients were evaluated by ECG for diagnosis of AV block. Two groups were made. Group 1 with complete heart block and group 2 without complete heart block. Patients were followed up for management as well as for determination of in hospital outcomes. Mean and standard deviations were calculated for quantitative variables like age. Frequency and percentage were calculated for qualitative variables like gender, obesity, complete AV block, smoking hypertension, dyslipidemia, diabetes Mellitus and family history. Effect modifiers were controlled through stratification. Chi square test was applied after stratification to see the effects of the outcome and $p$ value $<0.05$ was considered as significant. Data was analyzed with SPSS -23.

\section{RESULTS}

A total number of 167 patients were enrolled in the study, out of which $103(61.6 \%)$ were male while $64(38.4 \%)$ were female. Mean age of the patient was $50.5+10$. Patients with anterior wall $\mathrm{Ml}$ were $85(50.8 \%)$ inferior wall $\mathrm{Ml}$ were $63(37.7 \%)$ and lateral wall $\mathrm{Ml}$ in $18(10.77 \%)$. The mean duration of presentation to hospital after STEMI was $8.05+4.05$ hours. out of 167 patients ten $(5.9 \%)$ patients developed complete heart block. We distributed the patients in two groups on the basis of presence or absence of complete heart blocks. 7 (70\%) patients out of 10 having $\mathrm{CHB}$ were expired while 2 patients discharged and one patient referred for permanent pacemaker or revascularization. In second group 23 (15\%) patients were expired out of 157 patients, $110(70 \%)$ were discharged while $24(15 \%)$ were referred for invasive management. Overall mortality was $17.96 \%(30)$ No significant association was found between heart blocks and various clinical variables like age, gender, smoking, hypertension, diabetes, dyslipidemia, family history and obesity. All the 10 patients who developed AV blocks received conservative management and temporary pacemaker. Duration of follow up was only during hospital stay. In comparison between groups patients with inferior wall $\mathrm{Ml}$ developed $\mathrm{CHB}$ in $6(60 \%)$ patients as compared to anterior wall $\mathrm{Ml}$ in $2(20 \%)$ and lateral wall MI $2(20 \%)$ patients. Overall mortality in our patients with STEMI was $17.96 \%$ (30) and CHB complicating STEMI was $4.19 \%$.

\begin{tabular}{|c|c|c|}
\hline & & $\mathbf{N}(\%)$ \\
\hline & $\mathrm{Age}^{\mathrm{a}}$ & $50.50 \pm 10$ \\
\hline & Duration of presentation $^{a}$ & $8.05 \pm 4.05$ \\
\hline \multirow{2}{*}{ Gender } & Male & $103(61.6 \%)$ \\
\hline & Female & $64(38.4 \%)$ \\
\hline \multirow{2}{*}{ Hypertension } & Present & $81(48.5 \%)$ \\
\hline & Absent & $86(51.5 \%)$ \\
\hline \multirow{2}{*}{ Diabetes } & Present & $62(37.1 \%)$ \\
\hline & Absent & $105(62.9 \%)$ \\
\hline \multirow{2}{*}{ Smoking } & Present & $76(45.5 \%)$ \\
\hline & Absent & $91(54.5 \%)$ \\
\hline \multirow{2}{*}{ Family history } & Present & $41(24.5 \%)$ \\
\hline & Absent & $126(75.5)$ \\
\hline \multirow{2}{*}{ Dyslipidemia } & Present & $17(10.1 \%)$ \\
\hline & Absent & $150(89.9 \%)$ \\
\hline \multirow{2}{*}{ Obesity } & Present & $64(38.3)$ \\
\hline & Absent & $103(61.6 \%)$ \\
\hline \multirow{2}{*}{$\begin{array}{l}\text { Complete AV } \\
\text { block }\end{array}$} & Present & $10(5.95)$ \\
\hline & Absent & 157 (94.01\%) \\
\hline
\end{tabular}

Table-I. Clinical characteristics of patients in the study.

\begin{tabular}{|c|c|c|c|c|}
\hline & $\begin{array}{c}\text { Complete } \\
\text { AV block } \\
\mathbf{N}\end{array}$ & Present & Absent & $\begin{array}{c}\text { P. } \\
\text { Value }\end{array}$ \\
\hline \multirow{3}{*}{$\begin{array}{l}\text { Age group } \\
\text { (years) }\end{array}$} & $35-45$ & 4 & 57 & \multirow{3}{*}{$0.38^{*}$} \\
\hline & $46-54$ & 4 & 50 & \\
\hline & $>55$ & 2 & 50 & \\
\hline \multirow{2}{*}{ Gender } & Male & 8 & 127 & \multirow{2}{*}{$0.62^{*}$} \\
\hline & Female & 2 & 30 & \\
\hline \multirow{2}{*}{ Smoking } & Present & 5 & 71 & \multirow{2}{*}{$0.774^{\star}$} \\
\hline & Absent & 5 & 86 & \\
\hline \multirow{2}{*}{ Hypertension } & Present & 4 & 77 & \multirow{2}{*}{$0.56^{\star}$} \\
\hline & Absent & 6 & 80 & \\
\hline \multirow{2}{*}{ Diabetes } & Present & 3 & 59 & \multirow{2}{*}{$0.37 *$} \\
\hline & Absent & 7 & 98 & \\
\hline \multirow{2}{*}{ Dyslipidemia } & Present & 2 & 15 & \multirow{2}{*}{$0.82^{*}$} \\
\hline & Absent & 8 & 142 & \\
\hline \multirow{2}{*}{ Family history } & Present & 1 & 40 & \multirow{2}{*}{$0.16^{\star}$} \\
\hline & Absent & 9 & 117 & \\
\hline \multirow{2}{*}{ Obesity } & Present & 4 & 60 & \multirow{2}{*}{$0.43^{*}$} \\
\hline & Absent & 6 & 97 & \\
\hline
\end{tabular}

Table-II. Co-relation of atrioventricular block with other clinical features. 


\begin{tabular}{|c|c|c|c|c|c|c|}
\hline \multirow{3}{*}{ Type of MI } & \multicolumn{6}{|c|}{ Complete Heart Block } \\
\hline & \multicolumn{3}{|c|}{ Present 10(5.9\%) } & \multicolumn{3}{|c|}{ Absent 157 (94.1\%) } \\
\hline & Expired & Discharged & Referred & Expired & Discharged & Referred \\
\hline Anterior wall MI & $2(20 \%)$ & $1(10 \%)$ & $1(10 \%)$ & $13(8.2 \%)$ & $50(31.8 \%)$ & $10(6.3 \%)$ \\
\hline Inferior wall MI & $4(40 \%)$ & $1(10 \%)$ & & $6(3.82 \%)$ & $48(30.5 \%)$ & $8(5.9 \%)$ \\
\hline Lateral wall MI & $1(10 \%)$ & & & $4(2.54 \%)$ & $12(7.6 \%)$ & $6(3.82 \%)$ \\
\hline
\end{tabular}

\section{DISCUSSION}

In this study we observed that complete heart block is associated with STEMI and high inhospital mortality. Incidence of $\mathrm{CHB}$ is higher in inferior wall $\mathrm{Ml}$ as compared to anterior or lateral wall Ml. The incidence of $\mathrm{CHB}$ in inferior wall $\mathrm{MI}$ in pre-thrombolytic era was $19 \%^{8}$ while in TAMI (thrombolysis and angioplasty in myocardial infarction) study incidence was reduced to13\% due to thrombolytic therapy. ${ }^{9}$ In comparison with other studies frequency of CHB after STEMI in our study was $5.9 \%$ higher than what observed in previous studies ${ }^{10-12}$, this was due to unavailability of facility of early invasive reperfusion therapy. We also observed that the CHB in inferior wall $\mathrm{MI}$ was transient mostly and by thrombolytic therapy it was reversed. Very few patients needed referral for permanent pacemaker. But in anterior wall $\mathrm{Ml}$ it was persistent and malignant. ${ }^{9}$ Patient needed referral for permanent pacemaker and revascularization. Thrombolytic agents are very effective for reversal of complete heart block in most of the patients. In previous studies in-hospital mortality was reported $20-30 \%$ in patients with CHB complicating STEMI but in our study it was $4.19 \%$. Reduced mortality in our study was due to early use of thrombolytic therapy and patient care and early referral for PPM or revascularization if needed. Mortality can be further reduced by use of primary coronary intervention facility. ${ }^{12}$ Other poor prognostic factors noted were late presentations, late for thrombolytic therapy, multiple risk factors, co morbidities, anterior wall Ml, right ventricular dysfunction, cardiogenic shock and severe left ventricular systolic dysfunction.

\section{CONCLUSION}

Complete heart block is a known complication of patients with STEMI and is associated with poor prognosis. $\mathrm{CHB}$ in inferior wall $\mathrm{Ml}$ is more common than anterior wall MI. Thrombolytic agents are very useful in patients with STEMI for reversal of $\mathrm{CHB}$ in most of the patients. Overall mortality can be further reduced with the use of early invasive percutaneous coronary intervention.

Copyright $\odot 19$ Nov, 2020.

\section{REFERENCES}

1. Nicod P, Gilpin E, Dittrich H, et al. Long-term outcome in patients with inferior myocardial infarction and complete atrioventricular block. J Am Coll Cardiol 1988; 12:589-94.

2. Meine TJ, Al-Khatib SM, Aleander JH, et al. Incidence, predictors, and outcomes of high degree atrioventricular block complicating acute myocardial infarction treated with thrombolytic therapy. Am Heart J 2005; 149:670-4.

3. Nguyen HL, Lessard D, Spencer FA, et al. Thirty-year trends (1975-2005) in the magnitude and hospital death rates associated with complete heart block in patients with acute myocardial infarction: A population-based perspective. Am Heart J 2008; 156:227-33.

4. Cheng S, Keyes MJ, Larson MG. Long-term outcomes in individuals with prolonged PR interval or first-degree atrioventricular block. JAMA. 2009; 301(24):2571-2577. doi: 0.1001/jama.2009.888.

5. Gang UJO, Hvelplund A, Pedersen S, Iversen A, Jøns C, Abildstrøm SZ, et al. High-degree atrioventricular block complicating ST-segment elevation myocardial infarction in the era of primary percutaneous coronary intervention. November 2012, Pages 16391645.

6. Europace 2012;14(11):1639-45.Auffret V, Loirat A, Leurent G, Martins RP, Filippi E, Coudert I, et al. High-degree atrioventricular block complicating ST segment elevation myocardial infarction in the contemporary era. Heart 2016; 102(1):40-9. 
7. Grajek S, Lesiak M, Araszkiewicz A, Pyda M, Skorupski W, Grygier M, et al. Short and long term mortality in patients with ST-elevation myocardial infarction treated with different therapeutic strategies. Kardiol Pol. 2008; 66:154-163.

8. Aplin M, Engstrom T, Vejlstrup NG, et al. Prognostic importance of complete atrioventricular block complicating acute myocardial infarction. Am J Cardiol 2003; 92:853-6.

9. Berger PB, Ryan TJ. Inferior infarction: High risk subgroups Circulation 1990;401-11

10. Gupta T, Harikrishnan P, Kolte D, et al. Trends in management and outcomes of ST elevation myocardial infarction in patients with end-stage renal disease in the United States. Am J Cardiol2015; 115:1033-41.
11. Spencer FA, Jabbour S, Lessard D, et al. Twodecade-long trends (1975-1997) in the incidence, hospitalization, and long-term death rates associated with complete heart block complicating acute myocardial infarction: A community-wide perspective. Am Heart J 2003; 145:500-7.

12. Elixhauser A, Steiner C, Harris DR, Coffey RM. Comorbidity measures for use with administrative data. Med Care 1998; 36:8-27.

13. Gang UJ, Hvelplund A, Pedersen S. High-degree atrioventricular block complicating ST-segment elevation myocardial infarction in theera of primary percutaneous coronary intervention. Europace 2012; 14:1639-45.

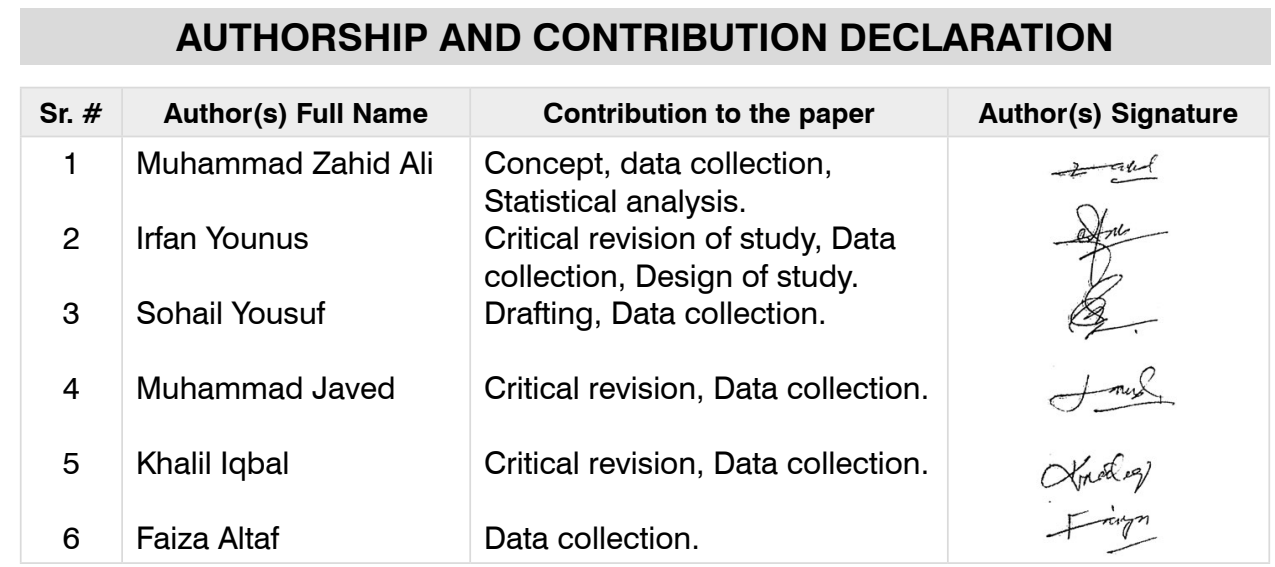

